\title{
Relationship between personality traits (introversion-extroversion) and control source with coping skills in six-grade elementary school students in Ghaemshahr city
}

\author{
Seyedeh Zhila Saber ${ }^{1}$, Rajabali Mohammadzadeh ${ }^{2}$ \\ ${ }^{1}$ Ph.D. Student of Educational Psychology- Islamic Azad University, Babol Branch, Iran. \\ ${ }^{2}$ Assistant Professor, Department of Psychology, Payame Noor University, Tehran, Iran.
}

\begin{tabular}{|c|c|}
\hline ARTICLE INFO & ABSTRACT \\
\hline $\begin{array}{l}\text { Keywords: } \\
\text { personality traits, } \\
\text { introversion, } \\
\text { extroversion, control } \\
\text { source, coping skills. }\end{array}$ & $\begin{array}{l}\text { The purpose of this study was to investigate the relationship between } \\
\text { personality traits (introversion-extraversion) and the source of } \\
\text { control with coping skills in sixth-grade elementary school students } \\
\text { in Ghaemshahr city. This research is applied in terms of purpose and } \\
\text { in terms of method, was a descriptive correlation research. The } \\
\text { statistical population of this study consists of } 3,379 \text { six-grade } \\
\text { elementary school students in Ghaemshahr city. Based on Krejcie } \\
\text { and Morgan (1970) table, } 346 \text { students were selected by stratified } \\
\text { random sampling method based on gender. To collect data, Eysenck } \\
\text { Personality Inventory (1965) with } 57 \text { questions, Rutter's Source } \\
\text { Control Questionnaire (1966) with } 29 \text { questions, and Lazarus and } \\
\text { Volkman's Coping Skills Questionnaire (1988) with } 66 \text { questions } \\
\text { was used. Validity and reliability of tools was confirmed. To analyze } \\
\text { the data, Pearson correlation and multivariate regression were used. } \\
\text { The results showed that there is a positive and significant relationship } \\
\text { between the personality trait of introversion and the source of control } \\
\text { with the coping skills of the emotional-focused, but there is a } \\
\text { negative and significant relationship between the personality trait of } \\
\text { extraversion and the coping skill of the emotional-focused. Also, } \\
\text { there is a positive and significant relationship between the personality } \\
\text { trait of extraversion and the problem-oriented coping skill, but there } \\
\text { is a significant negative relationship between the control source and } \\
\text { the problem-oriented coping skill, but there is no significant } \\
\text { relationship between the personality trait of introvert and the } \\
\text { problem-oriented coping skill. }\end{array}$ \\
\hline
\end{tabular}

\section{Introduction}

There are many ups and downs in every person's life that cause life interesting and exciting, until they are not too extreme. But those who are under intense stress must gain the required skills to reduce the effects of stress on their body and mind; otherwise their and others' mental health will be exposed to damage. Today, in spite of making profound cultural changes and changing lifestyles, many people in facing with problems in life don't have the necessary and basic abilities to solve their problems, and this causes their vulnerability in facing the issues of daily life (Salek Haddadi and Badri, 2013).

Coping skills are cognitive and behavioral attempts of the individual that is used to interpret and modify a stressful situation and reduce the suffering due to it (Lopes Et al., 2003). In general, coping skills refer to cognitive and behavioral efforts to prevent, manage and reduce stress (Yu et al., 2016). Lazarus and Folkman (1984) define coping as cognitive and behavioral

* Corresponding Author E-Mail Address: Seyedezhila.saber@gmail.com 
attempts to manage external and internal demands. Cognitive efforts can be external (problemoriented) and internal (emotional-focused). The emotional-focused coping describes the ways in which one focuses on himself and his entire effort is to reduce his unpleasant feelings (Dehghani and Kajbaf, 2013). The problem-oriented coping involves activities such as problem solving and awareness (Mazlum Bafruei et al., 2013).

However, coping skills include a set of efforts that individuals do to prevent factors threatening health but always the use of any coping skill is not associated with reducing stress, but its effectiveness varies in different situations (Akbari et al., 2009).

Longitudinal and cross-sectional studies suggest that one of the variables that can predict coping skills is personality (Marnie, 2008; Van Berkel, 2009; Lova et al., 2014). Personality is a collection of psychological characteristics that can categorize individuals based on it. These personality traits have a lasting effect on behavior, and based on these, it can be determined the specific behaviors of people in various educational and occupational contexts (Jafari et al., 2012). The role of personality traits on behavior and cognition is sometimes direct and without mediator and sometimes by influencing intermediary factors causes behavioral and cognitive outcomes (Nadi Ravandi et al., 2015).

Some specific personality traits cause individuals in a variety of situations display balanced and adaptive behaviors. Having the awareness and knowledge about personality and some behaviors are not used in different stages of personality development, but this knowledge in preventing or acting on the occurrence of disturbances and personality disorders can help individual. (Saroghad et al., 2011).

On the other hand, the control source is also a personality trait first introduced by Rotter in 1966 in line with the theory of social learning. Rotter defines the control source as the general expectation of individual from the outcome of an event that exists inside or outside of his personal control and understanding. On the one hand, people with a personality attribute of external control source perceive events beyond their control and attribute the results and outcome of the event to luck, fortune, or under control of others, or believe that events due to the complexities in the environment are unpredictable. Individuals with a personality trait of internal control source believe that events depend on their fairly permanent behavior and characteristics. Such people believe that they can influence their results through rewards, abilities, skills and attributes (Ahmadian, 2013).

In a research entitled "Relationship between Personality Traits and Stress Coping Strategies with Academic self-handicapping of Second and Third-grade High School Students in Ilam City", Mikaeli et al. (2017) showed that: Neuroticism, Extroversion, Openness to Experience, agreeing, and emotional-focused coping with students' academic self-handicapping is positively related; Sabrjo et al. (2015), in a research entitled "The Relationship between Source Control and Stress Coping Strategies in Primary School Students in Gilan Gharb City "showed that male students use more coping strategies with emotional-focused and problem-oriented stress but female students use more coping strategy of avoidance-oriented. Also, students with internal control source use more problem-oriented coping strategy and students with external control source use more emotional-focused coping strategy; Nadi Ravandi et al. (2015), in a research entitled" The relationship between personality traits and coping strategies with perceived stress level in nurses "showed that there is a significant and positive correlation between neuroticism and coping strategy with emotional-focused stress, between extraversion feature and coping strategy of problem and avoidance-oriented stress, also between consistency and conscientiousness features with coping strategies of problem-oriented stress; Ahmadian (2013), in a research entitled "Relationship between Personality Traits and Control Source with Test Anxiety among High School Students in Birjand," showed that there is a negative and significant relationship between test anxiety and extroversion. Also, the control source with test anxiety also had a positive and significant relationship; Sarvghad et al. (2011), in a research 
entitled "The Relationship between Personality Traits with Perfectionism and Coping Styles in Female and Male Students of Azad University of Marvdasht "showed that; There is a positive and significant relationship between personality traits (extroversion factors, openness, consistency and conscientiousness) and positive perfectionism. There is a positive and significant relationship between neuroticism and negative perfectionism. There is a positive and significant relationship between neuroticism and emotional-focused coping strategies, and there is a negative and significant relationship between consistency and emotional-focused coping strategies. Also, there is a positive relationship between conscientiousness and problemoriented coping styles.

Kardum and Krapik (2010), in a research entitled "The relationship between personality traits and stress coping strategies", showed that individuals with high neuroticism in facing with stressful situations use passive strategies such as avoidance, self-blame, wishful thought as well as interpersonal militancy-based approaches, such as hostile reaction and emotional evacuation. Delahaij et al. (2010) in a research entitled "The relationship between the style of coping with psychological hardiness" showed that ; There is a significant relationship between the style of coping with psychological hardiness and the coping style of people with high hardiness in stressful situations is the most efficient and Rodriguer (2010), in a study entitled "The relationship between emotional intelligence and coping strategies with stress in medical students" showed that there is a significant relationship between emotional intelligence and coping strategy. Also, low emotional intelligence scores were associated with coping strategies that were less effective.

Awareness of personality traits is useful and effective in coping effectively with life problems. Since personality traits are deeply related to how the individual perceives and interprets the world and its reaction to stressful events, it is natural that some personality traits are more flexible than other features. Individuals with inflexible personality traits, as well as those who cannot adapt their responses to a particular situation don't have life skills and show the worst reactions to life. Therefore, given that students at the sixth grade of elementary school are from the childhood stage to adolescent, they must have the necessary skills to deal with stress as well as adaptation to the environment. Therefore, the purpose of this study is to investigate the relationship between personality traits (introversion-extroversion) and the source of control with coping skills in six-grade elementary school students in Ghaemshahr city. To achieve this general goal, the following questions have been raised:

1- Is there a relationship between personality traits (introversion-extroversion) and control source with emotional-focused coping skill in students?

2- Is there a relationship between personality traits (introversion-extroversion) and the source of control with problem-oriented coping skills in students?

\section{Research Methodology}

The purpose of this study is applied and in terms of method is a descriptive correlational type. The statistical population of this study consists of 3,379 six-grade elementary school students (1691 girls and 1688 boys) in Ghaemshahr city, which according to Krejcie and Morgan (1970) table, 346 students (174 girls and 172 boys) were selected by stratified random sampling method based on gender at $95 \%$ confidence level and a measurement error of $\alpha=0.05$. Data gathering tools in this research are:

1- Eysenck Personality Questionnaire (1965): This questionnaire contains 57 questions and two dimensions of introversion and extroversion, which is designed as "Yes" and "No". If individuals answer Yes to the questions 1, 3, 8, 10, 12, 17, 22, 25, 27, 39, 41, 44, 46, 49, 53, 56 and answer No to the questions 5, 15, 20, 29, 32, 34, 37, 51, they are extroverted, and if they answer Yes to the questions 2, 4, 7, 9, 11, 14, 16, 19, 21, 23, 26, 28, 31, 33, 35 , 38, 40, $43,45,47,50,52,55$, and 57, they are introverted. Questions 6, 12, 18, 24, 30, 36, 42, 48 and 
54 are also lie detector. In this research, the face and content validity of the tool was confirmed by experts and its reliability was calculated using Cronbach's alpha coefficient of 0.85 , which is statistically significant and validated.

2- Rutter Control Source Questionnaire (1966): This questionnaire contains 29 items; each item has a pair of questions (A and B). Questions A get score one and questions B get score zero. 23 items measures the internal and external aspects of the control source, and 6 other articles $(1,8,14,19,24$ and 28$)$ are designed to cover the test purpose. Individuals who score 9 or more in this test will have an external control source and those who score less than 9 will have an internal control source. In this research, the face and content validity of the tool was confirmed by the experts and its reliability was calculated using Cronbach's alpha coefficient 0.74, which is statistically significant and validated.

3- Lazarus and Volkman Coping Skills Questionnaire (1988): This questionnaire consisted of 66 questions and two components (emotional-focused skill and problem-oriented skill) were designed in the 4-degree range, which scored, respectively, from zero to 3. Questions 5-6-710-11-12-13-14-15-16-17-21-28-33-34-35-40-41-43-44-46-47-54- 57-59-62-63 measures emotional-focused skills and questions 1-3-8-9-18-20-22-23-25-26-29-31-36-38-39-42-4548-49-51-52-56-60 measure problem-oriented skill and the questions of 19-24-27-30-32-3750-53-55-58-61-64 -65-66 were considered as deviant questions. In this research, the face and content validity of the tool was confirmed by the experts and its reliability was calculated using Cronbach's alpha coefficient 0.89 , which is statistically significant and validated. To analyze the data in the descriptive statistics section, the mean and standard deviation were used and in the inferential statistics, Pearson correlation tests and multivariate regression were used. Data analysis was done using SPSS20 software.

\section{Findings}

In Table 1, descriptive indicators such as mean and standard deviation of research variables are observed.

Table 1: Mean and standard deviation of research variables

\begin{tabular}{|l|c|c|c|}
\hline Variables & $\begin{array}{c}\text { Number of } \\
\text { samples }\end{array}$ & Mean & SD \\
\hline Introversion personality trait & 346 & 14.25 & 3.148 \\
\hline Extroversion personality trait & & 15.53 & 3.809 \\
\hline Source of control & & 11.502 & 3.741 \\
\hline Emotional-focused coping skill & & 44.46 & 4.981 \\
\hline Problem-oriented coping skill & & 40.39 & 7.716 \\
\hline
\end{tabular}

1. Is there a relationship between personality traits (introversion-extroversion) and control source with emotional-focused coping skills in students?

Table 2: Pearson correlation test results in Question 1

\begin{tabular}{|l|c|c|c|}
\hline \multirow{2}{*}{ Variable } & \multicolumn{3}{|c|}{ Emotional-focused coping skill } \\
\cline { 2 - 4 } & $\begin{array}{c}\text { Number of } \\
\text { samples (n) }\end{array}$ & Sig & $\begin{array}{c}\text { Correlation } \\
\text { value (r) }\end{array}$ \\
\hline Introversion personality trait & 346 & 0.0001 & $0.264^{* *}$ \\
\hline Extroversion personality trait & 346 & 0.0001 & $-0.392^{* *}$ \\
\hline Source of control & 346 & 0.0001 & $0.324 * *$ \\
\hline
\end{tabular}


According to Table 2, the correlation coefficient for introversion personality trait variables $(r=0.264)$, extroversion personality trait $(r=-0.392)$ and control source $(r=0.324)$; Given that significance level was calculated less than 0.05 ( $\mathrm{sig}<0.05)$ for the test of the relationship between personality traits (introversion-extroversion) and the source of control with emotionalfocused coping skills, so it can be concluded with \%99 confidence level that there is a positive and significant relationship between the introversion personality trait and the source of control with the emotional-focused coping skill, but there is a negative and significant relationship between the extroversion personality trait and the emotional-focused coping skill.

Multivariate regression test has been used to determine whether personality traits (introversion-extroversion) and control source have the ability to predict the emotional-focused coping skills, the results of which are presented in Table 3.

Table 3: Results of Multivariate Regression in Question 1

\begin{tabular}{|c|c|c|c|c|c|c|c|}
\hline Prediction variables & $\mathrm{F}$ & Sig & $\mathrm{R}$ & $\mathrm{R}^{2}$ & $\beta$ & $\mathrm{T}$ & Sig \\
\hline Fixed number & \multirow{4}{*}{47.474} & \multirow{4}{*}{0.0001} & \multirow{4}{*}{0.542} & \multirow{4}{*}{0.294} & - & 21.61 & 0.0001 \\
\hline Introversion personality trait & & & & & 0.299 & 6.484 & 0.0001 \\
\hline Extroversion personality trait & & & & & -0.308 & -6.535 & 0.0001 \\
\hline Source of control & & & & & 0.291 & 6.106 & 0.0001 \\
\hline
\end{tabular}

According to Table 3, considering that the significance level of the F statistic is calculated smaller than 0.05 ( $\mathrm{Sig}=0.0001)$, it indicates the validity of the regression model. According to this table, because at the confidence level of $95 \%$ and error of measuring $\alpha=0.05$, the significance level for all variables is calculated less than 0.05 ( $\mathrm{Sig}=0.05)$. Therefore, it can be concluded that in the simultaneous regression, the personality trait of introversion and the source of control can predict emotional-focused coping skill positively and personality trait of extroversion negatively. The value of $\mathrm{R} 2$ indicates that about $30 \%$ of the variance of the emotional-focused coping skill is explained by personality traits (introversion-extroversion) and the source of control.

2. Is there a relationship between personality traits (introversion-extroversion) and the source of control with problem-oriented coping skill in students?

Table 4: Results of Pearson correlation test in question two

\begin{tabular}{|l|c|c|c|}
\hline Variable & \multicolumn{3}{|c|}{ Problem-oriented coping skill } \\
\hline & $\begin{array}{c}\text { Number of } \\
\text { samples (n) }\end{array}$ & Sig & $\begin{array}{c}\text { Correlation } \\
\text { value (r) }\end{array}$ \\
\hline Introversion personality trait & 346 & 0.468 & 0.039 \\
\hline Extroversion personality trait & 346 & 0.0001 & $0.503^{* *}$ \\
\hline Source of control & 346 & 0.0001 & $-0.314^{* *}$ \\
\hline
\end{tabular}

** At the level of 0/99 was significant. * At the level of 0.95 was significant.

According to Table 4, the correlation coefficient for introversion personality trait variables ( $\mathrm{r}$ $=0.039)$, extroversion personality trait $(r=0.503)$ and control source $(r=0.314)$; Given that significance level was calculated less than $0.05(\operatorname{sig}<0.05)$ for the test of the relationship between personality traits of extroversion) and the source of control with emotional-focused coping skill, so it can be concluded with \%99 confidence level that there is a positive and 
significant relationship between the extroversion personality trait and the problem-oriented coping skill, but there is a negative and significant relationship between the control source and the problem-oriented coping skill. Also, the significance level for introversion personality trait was calculated to be greater than 0.05 ( $\mathrm{Sig}>0.05$ ); therefore, there is not a significant relationship between the personality trait of introversion and the problem-oriented coping skill. Multivariate regression test has been used to investigate whether personality traits (introversion-extroversion) and control source have the ability to predict the problem-oriented coping skills, the results of which are presented in Table 5.

Table 5: Results of Multivariate Regression in Question 2

\begin{tabular}{|c|c|c|c|c|c|c|c|}
\hline Prediction variables & $\mathrm{F}$ & Sig & $\mathrm{R}$ & $\mathrm{R}^{2}$ & $\beta$ & $\mathrm{T}$ & Sig \\
\hline Fixed number & \multirow{4}{*}{46.616} & \multirow{4}{*}{0.0001} & \multirow{4}{*}{0.539} & \multirow{4}{*}{0.29} & - & 10.53 & 0.0001 \\
\hline Introversion personality trait & & & & & 0.024 & 0.51 & 0.61 \\
\hline Extroversion personality trait & & & & & 0.454 & 9.6 & 0.0001 \\
\hline Source of control & & & & & -0.195 & -4.077 & 0.0001 \\
\hline
\end{tabular}

According to Table 5, considering that the significance level of the F statistic is calculated smaller than 0.05 ( $\mathrm{Sig}=0.0001)$, it indicates the validity of the regression model. According to this table, because at the confidence level of $95 \%$ and error of measuring $\alpha=0.05$, the significance level for personality trait of extroversion is calculated less than 0.05 ( $\mathrm{Sig}=0.05$ ). Therefore, it can be concluded that in the simultaneous regression, the personality trait of extroversion can predict problem-oriented coping skill positively and source of control negatively. But the personality trait of introversion cannot predict problem-oriented coping skill. The value of R2 indicates that about $29 \%$ of the variance of the problem-oriented coping skill is explained by personality traits of extroversion and the source of control.

\section{Discussion and Conclusion}

Today, any change in a person's life, whether pleasant or unpleasant, requires a kind of adaptation. Skills to cope with changes in life and the tensions resulting from these changes vary in different people and in terms of different situations. Coping skills are a set of cognitive and behavioral attempts of the individual that is used to interpret and modify a stressful situation and reduce the suffering caused by it.

Sappington (2003) believes that in using coping skills, each individual acts in different ways, and nobody answers a stressful stimulus that others have answered it. Some people are very vulnerable to the effects of stressful stimuli, but in contrast, some others are very resistant. In his view, factors such as hereditary factors, personality factors and skills affect the vulnerability to stress. Coping skills lead to adaptation and positive and beneficial behaviors in the individual, which make it easier to accept social responsibilities, and individual will be faced with the demands, expectations and daily problems, especially in interpersonal relationships, without endangering self and others. Therefore, in this research, the relationship between personality traits (introversion-extroversion) and the source of control with coping skills in the six-grade elementary school students in Ghaemshahr city was investigated.

The results of this study showed that there is a positive and significant relationship between the personality trait of introversion and the source of control with emotional-focused coping skill, but there is a negative and significant relationship between personality trait of extraversion and emotional-focused coping skill. Also, there is a positive and significant relationship between the personality trait of extraversion and problem-oriented coping skill, but there is a negative and significant relationship between the control source and the problem- 
oriented coping skill, but there is no significant relationship between the personality trait of introversion and the problem-oriented coping skill. This finding is consistent with the research results of Sabrju et al. (2015) that students with an internal control source are more likely to use problem-oriented coping strategy, and Nadi Ravandi et al. (2015) showed that there is a positive significant correlation between extroversion feature and the problem-oriented coping strategy in nurses. In explaining this finding, it can be said that, since extroverted people look at problems as a challenge, and they have a collectivist spirit, when they encounter problems, they use social support, one of the ways of problem-oriented coping. Also, people with extraversion tend to have social activities, they are always trying and if they are faced with a problem, they try different ways to solve the problem, they like emotion and mobility, and hope to succeed in the future.

McCrae and Kasta (1980) believe that these people are feeling happy with being together, they have positive emotions, and are socially advanced and pioneering, that these attributes are related to problem-oriented coping skills. Because problem-oriented skill depends on the use of cognitive components appropriately, so when a person uses problem-oriented skill, communication skills will usually be activated positively and constructively. Also, in the possible explanation of the negative relationship between the source of control and the problem-oriented coping skill, it can say that people with a high-level source of control can better deal with stress events and adapt to it.

In the end, according to research findings, it is suggested that education managers to be conducted training courses on stress coping skills for students, so that students can use appropriate strategies to deal with stressful events.

\section{References}

Ahmadian, Naser, The Relationship between Personality Traits and Control Source with Test Anxiety in High School Students in Birjand, Journal of Educational Psychology, Vol. 10, No. 18, 2013, 20-1.

Akbari, Mehdi, Mohammad Alilou, Majid, Aslan Abadi, Naser, Correlation between Stress and Coping Styles with Coronary Heart Disease: The Role of Gender Agent, Journal of Psychiatry and Clinical Psychology of Iran, 2010, No. 4, 2009, 376-368.

Dehghani, Akram, Kajbaf, Mohammad Baqer, Hardiness Relationships with Stress Coping Styles in Students, Journal of Knowledge and Wellbeing, Vol. 8, No. 3, 2013, 118-112.

Delahaij, R., Gaillard, A.W.K., \& Vandam, k., (2010). Hardiness and the Response to Stressful Situations: investigating mediating processes. Personality and Individual Differences. 49 (5). 386-390.

Jafari, Asghar, Amiri Majd, Mojtaba, Esfandiari, Zahra, The Relationship between Personality Traits and Coping Styles with Job Stress in Nurses, Quarterly Journal of Nursing Management, Vol. 1, No. 4, 2012, 44-36.

Kardum, I. \& Krapic, N. (2010). Personality traits, stressful life events and coping styles in early edolescence. Personality and Individual Differences. 30 (2010). 503-515.

Lopes, P.N., Salovey, P., \& Straus, R. (2003). Emotional intelligence, personality and the perceived quality of social relationship. Personality and Individual Differences. 35 (3). 641658. 
Lova, S., Popscu, C., Lova, A., Camelia, D., Mihancea, P., \& Buzoianu, A. (2014). Personality traits in multiple sclerosis: association with mood and anxiety disorder in pomanian patients Sample. Human and Veterinary Medicine.6(4).1-18.

Marnie B, M. (2008). The Role of Personality Following the September $11^{\text {th }}$ Terrorist Attacks:Big Five Trait Combinations and Interactions in Explaining Distress and Coping. Unpublished Dissertation of PhD in Psychology and Social Behavior. California Univercity.

Mazlum Bafruiy, Nahid, Afkhami Ardakani, Mohammad, Shams Esfandabad, Hassan, Jalali, Mohammad Reza, A Simple, Multiple Relation Between Resilience and Hardiness with Emotional-focused and Problem-Oriented Coping Styles in Patients with Diabetes in Yazd, Quarterly Journal of Diabetes of Nursing Faculty and Midwifery in Zabol, Volume 1, Number 2, 2013, 49-39.

Mikaeli, Niloofar, Parzour, Parviz, Bazdar, Fatemeh, Hatamloo, Rahime, Relationship between Personality Traits and Stress Coping Strategies with Academic Self-handicaping of Second and Third High Schools female students in Ilam City, Quarterly Journal of Educational Psychology, Number Twenty Fifth, 2017, 104-89.

Nadi Ravandi, Maryam, Sedighi Arfaei, Fariborz, Berbari, Marzieh, The Relationship between Personality Traits and Coping Strategies with Perceived Stress in Nurses, Iranian Journal of Nursing, Volume Twenty-Eighth, Number 97, 2015, 22-11

Rodrigues, L. (2010). Investigating emotional intelligence, stress and copping srraregies in medical students. International journal of psychological stadies. 2(1).

Sabrju, Atefeh, Heidari, Farhad, Batmani, Parvin, The Relationship between Control Source and Stress Coping Strategies in Primary School Students in Gilan Gharb, The First National Conference on Strategies of Development and Promotion of Education Sciences, Psychology, Advice and Education in Iran, Tehran, Association of the Development and Promotion of Basic Sciences and Techniques, 2015.

Salek Haddadi, Negar, Badri, Rahim, Study of the Effect of Training of Life Skills on Coping Style, Quarterly of Education and Evaluation, Sixth Year, No. 21, 2013, 94-79.

Soroghad, Sious, Barzegar, Majid, Bolaghi, Tahereh, The Relationship between Personality Traits with Perfectionism and Stress Coping Methods in Female and Male Students of Marvdasht Azad University, Journal of Women Sociology, Vol. 2, No. Third, 2011, 101-81

Van Berke, H. (2009). The relationship between personality, coping styles and stress, anxiety and depression. unpublished dissertation Master of Science in Psychology. University of Canterbury.

Yu, B., Xu, H., Chen, X., \& Liu, L. (2016). Analysis of coping styles of elderly women patients with stress urinary incontinence. International Journal of Nursing Sciences. 3(2). 153-157. 